\title{
Compreensões de professores de Ciências acerca DE CURRÍCULO ESCOLAR: UMA REVISÃO BIBLIOGRÁFICA
}

\author{
UNDERSTANDINGS OF SCIENCE TEACHERS ABOUT SCHOOL CURRICULUM: \\ A BIBLIOGRAPHIC REVIEW
}

DOI: $\underline{\text { 10.23926/RPD.2526-2149.2020.v5.n2.p1211-1233.id783 }}$

\section{Kelly Karine Kreuz \\ Mestranda em Ensino de \\ Ciências (PPGEC/UFFS) \\ kelly.kkk@hotmail.com}

\section{Fabiane de Andrade \\ Leite}

Doutora em Educação nas

Ciências (UNIJUI)

Professora do Programa de

Pós-Graduação em Ensino de

Ciências (PPGEC/UFFS)

fabianeandradeleite@gmail.c om

\begin{abstract}
Resumo: Discussões acerca do currículo na Educação Básica têm sido recorrentes no contexto atual brasileiro, em que se busca qualificar os processos de ensinar e aprender em sala de aula. $\mathrm{O}$ objetivo do presente estudo foi analisar compreensões de professores da área de Ciências da Natureza acerca de currículo escolar. Por meio de uma pesquisa de natureza qualitativa utilizou-se como objeto de investigação, estudos acadêmicos obtidos na Biblioteca Digital Brasileira de Teses e Dissertações, que evidenciaram distintas compreensões entre os professores organizadas nas categorias de análise: compreensão conteudista-ingênuo sobre currículo escolar, compreensão curricular sob a perspectiva conteudista-crítica e currículo escolar sob uma compreensão crítico-reflexiva. A categoria compreensão conteudista-ingênuo sobre currículo escolar predominou nas pesquisas analisadas, que revelam compreensões restritas aos documentos curriculares e, ainda, evidencia dificuldades de os professores reconhecerem seu papel na construção curricular. Com o estudo, reitera-se afirmações já realizadas na literatura acadêmica, que deflagram o distanciamento entre a produção teórica acerca do currículo e a realidade das escolas.
\end{abstract}

Palavras-chave: Currículo de Ciências. Conteudista-ingênuo. Crítico-reflexiva.

\begin{abstract}
Discussions about the curriculum in Basic Education have been recurrent in the current brazilian context, in which it seeks to qualify the processes of teaching and learning in the classroom. The aim of the present study was to analyze understandings of teachers in the field of Natural Sciences about the school curriculum. Through research of a qualitative nature, academic studies obtained at the Brazilian Digital Library of Theses and Dissertations were used as an object of investigation, which showed different understandings among teachers organized in the analysis categories: content-naive, content-critic and critic-eflective. The content-naive category predominated in the researches analyzed, which reveal understandings restricted to curricular documents and, still, it shows difficulties for teachers to recognize their role in curriculum construction. With the study, it is reiterated statements already made in the academic literature, which trigger the distance between the theoretical production about the curriculum and the reality of the schools.
\end{abstract}

Keywords: Science Curriculum. Content-naïve. Critical-reflective. 


\section{INTRODUÇÃO}

$\mathrm{O}$ presente estudo tem como foco analisar a literatura acadêmica quanto às compreensões de professores de Educação Básica acerca do currículo educacional no Brasil. Tal temática é relevante na medida em que novas políticas curriculares têm sido propostas no Brasil nos últimos anos, como é o caso da nova Base Nacional Comum Curricular (BNCC). A partir de estudos relevantes da área do currículo, que se destacam por apresentarem discussões contemporâneas, e refletindo a respeito da importância em compreendermos os entendimentos dos professores de como o currículo é construído e, como o professor se reconhece no processo de construção curricular, apresentamos esta pesquisa realizada a partir de uma revisão de literatura em dissertações e teses brasileiras, que discutem compreensões dos professores da área de Ciências da Natureza $(\mathrm{CN})$ acerca de currículo.

Estudos relacionados ao currículo na Educação Básica têm sido temática presente em discussões que apresentam como objetivo qualificar os processos de ensino e de aprendizagem ao longo dos últimos vinte anos. No Brasil, as pesquisas tornaram-se mais intensas ao final do século XX, a partir do processo de redemocratização do ensino (KRASILCHIK, 2000). Destacamos que as pesquisas evidenciam que o campo do currículo tem apresentado "avanços, omissões e desafios a serem enfrentados" (MOREIRA, 2002, p. 83). Nossas intenções corroboram os entendimentos de Lopes e Macedo (2010, p. 18), quanto ao processo de analisar o campo do currículo, que "inclui tomar como objeto o conhecimento produzido pelos sujeitos investidos da legitimidade de falar sobre currículo. Tal legitimidade é conferida por sua presença em instâncias institucionalizadas".

Com essas perspectivas, buscamos apresentar reflexões acerca do currículo no ensino de Ciências no Brasil, com o olhar voltado aos principais atores que contribuem para o processo de recontextualização do currículo na prática, os professores. Nesse sentido, partimos das ideias de Lopes e Macedo (2011, p.41), ao definirem que:

[...] o currículo é, ele mesmo, uma prática discursiva. Isso significa que ele é uma prática de poder, mas também uma prática de significação, de atribuição de sentidos. Ele constrói a realidade, nos governa, constrange nosso comportamento, projeta nossa identidade, tudo isso produzindo sentidos. Trata-se, portanto, de um discurso produzido na interseção entre diferentes discursos sociais e culturais que, ao mesmo tempo, reitera sentidos postos por tais discursos e os recria.

No que se refere ao desenvolvimento do pensamento de professores da área de Ciências da Natureza (CN) destacamos o trabalho de Leite e Zanon (2018), que buscam analisar compreensões de professores acerca de currículo escolar. No trabalho, as autoras defendem o desenvolvimento de Estilos de Pensamento (EPs) que caracterizam tais compreensões e, 
amparadas nas categorias propostas por Fleck (2010), acenam o desenvolvimento de dois EPs, sendo um EP conservador em professores de Ciências e outro transformador. No estudo realizado, as autoras afirmam que, "percebemos que os professores, ora com estilos de pensamento conservador, apresentaram um sentido de autonomia unilateral e autoritária, enquanto os professores com estilos de pensamento transformador evidenciaram uma compreensão de autonomia compartilhada e coletiva" (LEITE; ZANON, 2018, p. 971). Destarte, as autoras identificaram perspectivas de currículo nos discursos docentes, que caracterizam os estilos de pensar e, com isso, contribuem com o presente estudo, pois possibilitam aproximações.

Considerando o currículo uma prática discursiva e de atribuição de sentidos, apoiamos a presente investigação em dois conceitos relevantes propostos, no Brasil, por Alice Casimiro Lopes. De acordo com a autora (2008), estudos curriculares devem ser analisados tendo como suporte teórico a recontextualização de discursos. Tal processo trata da reinterpretação a que são submetidos os documentos e as políticas curriculares no interior do espaço escolar. Ainda, destacamos, conforme apresentado por Lopes (2008), que a recontextualização de discursos ocorre por um processo de hibridismo, definido pela mistura de concepções e interpretações, com isso, "os discursos perdem as suas marcas originais" (2008, p. 31), e se unem a outras concepções para formar um híbrido. Nesse sentido, relacionando os conceitos, a autora propõe a categoria que chama de recontextualização por hibridismo, em que os discursos curriculares são reinterpretados e hibridizados considerando o contexto em que o sujeito se encontra.

É importante destacar ainda que, entende-se por discurso não apenas a linguagem falada e escrita, mas todas as interações do sujeito ao designar significados para alguma coisa. Além disso, as próprias regras de recontextualização se tornam responsáveis pela produção do discurso pedagógico, que, de acordo com Lopes e Macedo (2011), se caracteriza por não ter um teor exclusivo, se tratando de um composto de regras apropriadas de discursos diversos, e, que não são produzidos no contexto escolar, sendo, portanto, considerado "um princípio recontextualizador, que desloca e recoloca os discursos originais em novas bases sociais e em novas relações de poder e de controle (2011, p. 102)”.

Assim, atentamos à compreensão de professores da área de Ciências da Natureza acerca do currículo educacional brasileiro. Tal investigação se aproxima de um estudo apresentado por Lopes (2006), em que defende que os discursos curriculares podem ser analisados por meio de duas instâncias, sendo uma micro e outra macro. A abordagem macro trata de estudos de trabalhos 
[...] que focalizaram: as disposições legislativas, as propostas curriculares oficiais, incluindo a história dessas disposições propostas; a história das disciplinas no sistema educacional, seja por intermédio de documentos oficiais e/ou livros didáticos; a análise da organização curricular ou da seleção de conteúdos do currículo ou de um componente curricular específico no sistema educacional (LOPES, 2006, p. 624).

Já na abordagem micro, Lopes (2006, p. 625), situou trabalhos que focalizaram uma metodologia centrada na investigação

[...] do cotidiano da escola ou da prática pedagógica; das concepções dos sujeitos em uma dada instituição escolar ou da instituição escolar como um todo; do uso dos livros didáticos, incluindo a história do currículo com privilégio da investigação do cotidiano escolar; os estudos de caso de forma geral.

Nessa linha, Lopes (2006) contribui ao apresentar as perspectivas macro e micro dos discursos curriculares. Quanto a isso a autora entende

[...] ser possível evidenciar alguns modos de como tais relações (macro e micro), têm sido abordadas na educação, bem como construir um debate que favoreça a superação da dicotomia ainda presente na forma de algumas pesquisas entenderem a relação macro/micro...que os debates no campo do currículo se articulam com os debates mais amplos do campo educacional, de forma que este campo pode se beneficiar do entendimento de questões curriculares ( LOPES, 2006, p. 621-23).

Ainda, aferimos que o processo de estudo curricular, sob a perspectiva apresentada por Lopes (2006), considera que os discursos macro são recontextualizados em instâncias micro. Tal recontextualização ocorre por meio de um hibridismo de discursos, conforme a autora (2005, p. 56), "É a partir da ideia de uma mistura de lógicas globais, locais e distantes, sempre recontextualizadas, que o hibridismo se configura".

Nesse sentido, corroboramos as ideias da autora ao afirmar que, por vezes, as instâncias micro se veem demasiadamente afastadas da instância macro em virtude de que

[...] as instâncias micro são interpretadas como homogêneas, ou porque essa homogeneidade é considerada a priori, ou porque a heterogeneidade é suposta como possível de ser reduzida a elementos simples e fundamentais. Processos complexos e matizados a história das disciplinas, as políticas de currículo, a produção do conhecimento escolar, a produção de livros didáticos, as concepções de professores, a seleção e a organização dos conteúdos - tendem a ser simplificados por mecanismos de apagamento de suas diferenças e não por inclusão dessas diferenças em um sistema amplo de interpretação (LOPES, 2006, p. 627).

Ao apresentar a instância micro, Lopes (2006, p. 628), entende que "são frequentes estudos que focalizam a escola ou a sala de aula como uma unidade isolada, sendo o currículo desenvolvido em decorrência quase exclusiva das concepções dos sujeitos atuantes na prática". Assim, neste trabalho, a questão de pesquisa que se coloca é "Quais as compreensões de professores da educação básica acerca do currículo no ensino de Ciências?", sendo importante pontuar que os dados foram obtidos em pesquisas brasileiras e tiveram como foco o reconhecimento da responsabilidade da construção curricular pelo professor. Pretendemos 
responder a essa pergunta tendo como objetivo fornecer elementos para se (re)pensar as discussões do currículo em cursos de formação de professores em exercício.

No que se refere ao foco do presente estudo, as compreensões de professores da área de Ciências da Natureza, entendemos que podem ser caracterizadas pelos discursos pedagógicos compartilhados, sejam verbalizados ou escritos. Dessa forma, destacamos a importância em nos mantermos vigilantes quanto aos discursos curriculares construídos e recontextualizados no âmbito do espaço escolar (LOPES, 2005). Assim, apresentamos, na sequência, a metodologia escolhida para a construção da presente investigação e a discussão dos resultados identificados por meio do processo de análise.

\section{Aspectos Metodológicos}

Para compor a pesquisa, foram considerados estudos já realizados no âmbito acadêmico que tratam da temática. Para tanto, empreendemos um estudo de caráter qualitativo do tipo bibliográfico. De acordo com Lüdke e André (2013), a revisão bibliográfica é pertinente e importante em estudos qualitativos uma vez que pode indicar os questionamentos mais relevantes na literatura sobre o objeto pesquisado, além de revelar aspectos opostos ou relacionados entre diversos estudos e também, levantar a indagação acerca do que vem sendo negligenciado sobre o tema.

Assim, para traçar um quadro das pesquisas quanto à temática, foi realizada uma busca detalhada na Biblioteca Digital de Teses e Dissertações (BDTD) do IBICT (Instituto Brasileiro de Informação em Ciência e Tecnologias), um espaço de busca em que são disponibilizados trabalhos completos de teses e dissertações defendidas em todas as instituições de ensino e pesquisa do país. O acesso ao repositório é gratuito, o que contribui para uma maior visibilidade da produção científica nacional.

Os resultados foram produzidos com base na análise de conteúdo de Bardin (2011), a partir das etapas de organização, codificação, categorização e inferências. Na etapa da organização, a análise de conteúdo se estrutura fundamentalmente em três fases distintas, sendo elas a "pré-análise, a exploração do material e o tratamento dos resultados, a inferência e a interpretação" (BARDIN, 2011, p. 124).

Nesse sentido, caracterizando a fase da pré-análise, que consiste na organização do material de análise, a busca avançada foi realizada utilizando os descritores "currículo" e “ensino de ciências". Nessa, foram identificados 86 trabalhos, dos quais 28 teses de doutorado 
e 58 dissertações de mestrado. Cabe destacar, que o levantamento dos dados foi realizado no ano de 2019.

Na sequência, foi efetivada a fase de exploração do material, em que buscamos filtrar trabalhos que tivessem aproximação com o objetivo da presente pesquisa. Na leitura dos resumos dos 86 trabalhos, identificamos dez estudos, sendo três teses e sete dissertações que, apresentavam pesquisas contendo compreensões de professores acerca do currículo da educação básica brasileira. Os respectivos trabalhos são apresentados no Quadro 1, destacamos ainda que, de acordo com Bardin (2011, p. 133) "tratar o material é codificá-lo. A codificação corresponde a uma transformação", portanto os trabalhos estão identificados por P1, P2 e assim sucessivamente, indicando pesquisas acadêmicas.

Quadro 1 - Pesquisas acadêmicas sobre compreensões de professores acerca do currículo

\begin{tabular}{|c|c|c|c|}
\hline Identificação & Título & Tipo de trabalho & Ano \\
\hline $\mathrm{P} 1$ & $\begin{array}{l}\text { Os saberes de professores que ensinam ciências nas séries } \\
\text { iniciais - um estudo de caso. }\end{array}$ & Dissertação & 2005 \\
\hline $\mathrm{P} 2$ & $\begin{array}{l}\text { Atividade Interdisciplinar no ensino de Ciências: entre o ideal e } \\
\text { a realidade. }\end{array}$ & Dissertação & 2008 \\
\hline P3 & $\begin{array}{l}\text { Dez anos dos Parâmetros Curriculares Nacionais: contribuições } \\
\text { para o ensino de ciências naturais nos anos iniciais do ensino } \\
\text { fundamental I }\end{array}$ & Dissertação & 2010 \\
\hline $\mathrm{P} 4$ & $\begin{array}{l}\text { Tradição e inovação: sentidos de currículo que se hibridizam } \\
\text { nos discursos sobre o ensino de Ciências nos anos iniciais do } \\
\text { Ensino Fundamental }\end{array}$ & Tese & 2011 \\
\hline P5 & $\begin{array}{l}\text { Relação entre a formação docente para os anos iniciais e a } \\
\text { concepção dos professores sobre o ensino de ciências }\end{array}$ & Dissertação & 2013 \\
\hline P6 & $\begin{array}{l}\text { Currículo de Ciências da Natureza: O processo de reconstrução } \\
\text { do Projeto Político-Pedagógico na escola pública de Ensino } \\
\text { Médio }\end{array}$ & Tese & 2014 \\
\hline P7 & $\begin{array}{l}\text { A construção da interdisciplinaridade a partir dos saberes } \\
\text { docentes nas ciências naturais: a realidade de duas escolas } \\
\text { públicas do norte do Rio Grande do Sul }\end{array}$ & Dissertação & 2015 \\
\hline P8 & $\begin{array}{l}\text { Conhecimentos profissionais da docência no ensino de ciências } \\
\text { no contexto do programa São Paulo faz escola e do SARESP }\end{array}$ & Dissertação & 2016 \\
\hline P9 & $\begin{array}{l}\text { O currículo e o seu papel no ensino: compreensão de docentes } \\
\text { de ciências da natureza do ensino fundamental II de escolas } \\
\text { estaduais em Goiânia }\end{array}$ & Dissertação & 2018 \\
\hline P10 & $\begin{array}{l}\text { Interfaces disciplinares: ensaios e teorizações de práticas } \\
\text { educativas para integrar disciplinas no ensino de ciências }\end{array}$ & Tese & 2018 \\
\hline
\end{tabular}

Fonte: $\mathrm{O}(\mathrm{s})$ autor(es).

Os dez trabalhos selecionados foram produzidos entre 2005 a 2018 e são oriundos de diferentes programas de pós-graduação de Instituições de Ensino Superior de vários estados de todo o país e compõem o corpus da análise a partir da regra da homogeneidade defendida por Bardin (2011, p. 128), em que, segundo a autora, "os documentos retidos devem ser homogêneos, isto é, devem obedecer a critérios precisos de escolha e não apresentar demasiada 
singularidade fora desses critérios", com base nessa regra, alguns trabalhos não foram selecionados para o presente estudo.

Dentre estes os que tratavam de aspectos mais específicos em relação ao currículo como: a perspectiva Ciência, Tecnologia e Sociedade, História da Ciência, Educação Indígena, ou ainda estudos que investigam compreensões de professores em formação inicial ou em relação ao ensino superior. Outros critérios de exclusão referem-se a estudos com foco no conhecimento do aluno, em metodologias do currículo, educação especial, conceitos de disciplinas específicas, teorias da aprendizagem, ensino de ciências em outros contextos, tecnologias de Informação e Comunicação (TICs), formação continuada de professores, temas transversais, ENEM (Exame Nacional do Ensino Médio), saúde no ensino de ciências, atividades práticas, livros didáticos, alfabetização científica, e outros que não se aproximam do nosso tema de pesquisa. Além disso, alguns trabalhos que não apresentavam pesquisa empírica, os quais dificultam a compreensão de professores, também foram excluídos.

Com os dados organizados, passamos a realização de sucessivas leituras, que nos auxiliaram no processo de análise. Lüdke e André (2013, p. 50), contribuem ao propor que "depois de organizar os dados, num processo de inúmeras leituras e releituras, o pesquisador pode voltar a examiná-los para tentar detectar temas e temáticas mais frequentes”. Dessa forma, o processo de leitura e releitura dos trabalhos possibilitou organizar categorias que contribuíram para atender ao objetivo do presente estudo, que de acordo com as autoras (2013, p. 50), tratase de um "procedimento essencialmente indutivo".

Ainda, destacamos que, de acordo com Bardin (2011, p. 148), "classificar elementos em categorias impõe a investigação do que cada um deles tem em comum com outros. O que vai permitir o seu agrupamento é a parte comum existente entre eles". Assim, a autora (BARDIN, 2011), afirma que o processo de categorização pode envolver duas etapas, um em que as categorias já são pré-estabelecidas, denominado de "procedimento por "caixas"”' (2011, p. 149), e, o outro, quando as categorias não são fornecidas, todavia, resultam "da classificação analógica e progressiva dos elementos. Este é o procedimento por "acervo". O título conceitual de cada categoria somente é definido no final da operação" (2011, p. 149). Dessa forma, as categorias que emergiram do processo de análise estão apresentadas no quadro 2, e, caracterizam o processo de agrupamento das compreensões dos professores apresentadas nos estudos, sendo elas: compreensão conteudista-ingênuo sobre currículo escolar, compreensão curricular sob a perspectiva conteudista-crítica e currículo escolar sob uma compreensão crítico-reflexiva. 
Quadro 2 - Categorias sobre as compreensões dos professores acerca do currículo presentes nas Teses e Dissertações do BDTD

\begin{tabular}{|l|l|}
\hline Categorias & Trabalhos \\
\hline Compreensão conteudista-ingênuo sobre currículo escolar & P1, P2, P7, P8, P9, P10 \\
\hline Compreensão curricular sob a perspectiva conteudista-crítica & P3, P4, P5 \\
\hline Currículo escolar sob uma compreensão crítico-reflexiva & P6 \\
\hline
\end{tabular}

Fonte: $\mathrm{O}(\mathrm{s})$ autor(es).

As categorias foram denominadas com base em aspectos que caracterizaram os trabalhos, em que buscamos unidades de aproximação nas discussões apresentadas. Nesse sentido, a categoria compreensão conteudista-ingênuo sobre currículo escolar é caracterizada nas pesquisas que indicaram compreensões de professores relacionando currículo com documentos, um artefato construído sem a participação dos professores. Por meio da leitura dos 6 trabalhos alocados nessa categoria percebemos, que os professores compreendem o currículo, e, igualmente a sua construção, como algo que ocorre distante deles, afastado da realidade da escola, o que remete a apontar para uma tendência quanto à ingenuidade por parte dos professores que, ao longo de sua prática pedagógica operam como se fossem robôs. Conforme Lopes e Macedo (2011, p. 154), os professores em atividade na Educação Básica, "naturalizam currículos prescritos (ou tradicionais), sem questionar de onde vêm os conteúdos a serem ensinados", distribuindo conteúdos pré-estabelecidos por outras pessoas, de outras realidades sociais e econômicas, sem questionarem o porquê da importância deste ou daquele conteúdo, tais características deflagram certa ingenuidade do professor.

Já com a compreensão curricular sob a perspectiva conteudista-crítica identificamos trabalhos que depreendem uma compreensão de professores em relação ao currículo como uma grade curricular organizada fora da escola, porém com indícios de algum reconhecimento, por parte dos professores, e principalmente, da relevância da sua participação no processo. Os trabalhos apresentados nesta categoria, se aproximam ao demonstrarem algumas possibilidades do professor que se reconhece, ainda que apenas em determinados momentos, como um profissional que, sobretudo, possui uma responsabilidade social, ao ser professor e, que, por isso, demanda certa criticidade, uma vez que, de acordo com Lopes e Macedo (2011, p. 155), "as decisões curriculares que os docentes tomam sobre o que e como ensinar e sobre como avaliar devem ampliar as possibilidades de vida dos alunos".

A categoria currículo escolar sob uma compreensão crítico-reflexiva, identificada em um trabalho, caracteriza compreensões mais qualificadas do currículo, em que os professores se reconhecem no processo de construção curricular. Nessa compreensão curricular um dos elementos centrais é a reflexão, ao refletir sobre a sua prática, acerca do currículo que está 
compondo a sua atividade, o currículo vai sendo construído pelo próprio professor, ao se dar conta do que precisa melhorar, do que pode fazer diferente, do que deve adaptar à sua realidade e a de seus alunos. De acordo com Lopes e Macedo (2011, p. 152) "qualquer currículo formal é reescrito pelo professor, na medida em que ele reflete sobre a sua prática" e, ainda, segundo as autoras, a reflexão contribui ao fazer com que o docente se configure em um "formulador do currículo vivido nas escolas e a separação entre desenvolvimento e implementação curricular torna-se sem sentido" (2011, p. 252).

Nesse sentido, com as categorias identificadas apresentamos, a seguir, os resultados e discussões acerca da temática proposta.

\section{COMPREENSÕES ACERCA do CURRículo ESCOLAR EM PESQUiSAS bRASILEIRAS DE ENSINO DE CIÊNCIAS}

Nesta seção, trazemos para discussão os resultados da análise, na qual emergiram as categorias: compreensão conteudista-ingênuo sobre currículo escolar, compreensão curricular sob a perspectiva conteudista-crítica e currículo escolar sob uma compreensão crítico-reflexiva. Apoiados em alguns temas problematizados anteriormente, ao entendermos a importância de considerar a esfera macro, em que os documentos curriculares oficiais são produzidos, construindo discursos oficiais, que são recontextualizados, reinterpretados e hibridizados na instância micro, por meio das concepções de professores, produzindo discursos não oficiais, e que, dessa forma, refletem predominantemente nas compreensões dos professores. A partir delas, apresentamos e discutimos, como os professores da área de Ciências da Natureza, em exercício na Educação Básica, compreendem o currículo, o que nos proporcionou entendimentos acerca de estudos já realizados na temática proposta.

\subsection{COMPREENSÃO CONTEUDISTA-INGÊNUO SOBRE CURRÍCULO ESCOLAR}

Das compreensões dos professores a respeito do currículo escolar, apresentadas nos trabalhos pesquisados, percebemos que, prevaleceram os que compreendem o currículo tanto sob uma visão que o considera como o guia do processo de escolaridade, quanto numa interpretação que valoriza a utilização de um número excessivo de conteúdos, o que nos levou a categorizar os trabalhos na perspectiva conteudista-ingênuo, em que o afastamento entre a instância macro e a instância micro se evidencia explicitamente. No estudo, os trabalhos P1, P2, P7, P8, P9 e P10 se aproximaram dos critérios estabelecidos para essa categoria, sendo uma tese e cinco dissertações. 
Os aspectos que foram sinalizados com maior ênfase nos trabalhos, por meio dos discursos dos professores, destacam o currículo como artefato, um instrumento que tem origem em instâncias fora da escola de forma autoritária, conforme apontado em P7:

[..] O Ensino Médio Politécnico chegou às escolas em 2012 [...] P1 afirma que ainda há dúvidas sobre a proposta e isso pode comprometer um pouco a qualidade do trabalho desenvolvido. A professora P2 declara 'eu pouco sei sobre o Ensino Médio Politécnico' e isso faz com que seja difícil pôr em prática a proposta, opinião compartilhada pelas professoras P3 e P4 (CARMINATTI, 2015, p. 82, grifos da autora).

Com essa perspectiva, a autora destaca que "[...] acostumados com o currículo tradicional, dividido em disciplinas que não inter-relacionam-se, os professores estranharam a nova demanda de currículo interdisciplinar e integrado" (CARMINATTI, 2015, p. 82). A dissertação discute a implantação do Ensino Médio Politécnico no Rio Grande do Sul, que foi uma política curricular proposta para as escolas no ano de 2012 e, destaca, a resistência dos professores com a imposição, às escolas, de um novo currículo.

Nesse sentido, Lopes (2008, p. 38) afirma que, “essas interpretações restritas do currículo integrado, são decorrentes, em grande parte, de um apagamento da história das proposições de integração curricular”. A autora ainda salienta que esse apagamento ocorreu também com os parâmetros curriculares e que "tratar tais modalidades como novidade é ignorar muito do que os professores já realizam em suas práticas e muitos dos saberes que construíram ao longo de suas trajetórias profissionais" (LOPES, 2008, p. 39).

Nessa mesma linha, Braga (2005), autor de P1, apresenta o afastamento dos professores no processo de construção curricular. Para o autor, "os professores sentem-se afastados da elaboração dos currículos e programas oficiais que norteiam a Educação Básica" (BRAGA, 2005, p. 27). E continua, "através de documentos oficiais e seus derivados, como livros didáticos, cursos e reuniões elaboradas por coordenadores regionais, entre outros meios, que os professores tomarão contato com o currículo das ciências naturais e seus conteúdos" (BRAGA, 2005, p. 39).

A realidade apresentada por Braga (2005) é destacada também em P8, por Melo (2016) em um excerto de fala de uma professora participante da pesquisa:

(PI) ... quando eu vejo um tema novo... principalmente... eu falo e agora... tenho que planejar né... utilizo o currículo... lá eu vejo as competências e habilidades que tem que desenvolver... ai eu tento pensar... o que eu vou fazer em cima daquilo lá... porque o mesmo tema tem vários... ele abrange vários braços... aí eu gosto do currículo porque eu olho lá o que é a competência que é proposto para os alunos aprenderem e faço (MELO, 2016, p. 61). 
Melo (2016) discute a dependência dos professores pelos conteúdos prescritos em um documento na realização dos planejamentos de ensino e afirma que,

em outros termos, os professores convivem com documentos oficiais que, embora com status prescritivo de aprendizagens desejadas, mas sem natureza de currículo, designam ou fazem referência a desempenhos (habilidades) cuja compreensão ou tradução para as atividades cotidianas de ensino e de avaliação impõem conhecimentos adicionais (MELO, 2016, p. 61).

O distanciamento do currículo real e do prescrito na educação básica brasileira é destacado pelos autores como um entrave ao processo de construção curricular de forma qualificada. Tal perspectiva é recorrente nos trabalhos, o que reforça a compreensão conteudista-ingênuo, destacada, também, nos estudos de Melo (2016, p. 104), “foi possível verificar, por meio de sinalizações, que há um abismo entre a prática docente e as avaliações em larga escala, pois as intenções não se conectam".

A falta de reconhecimento dos professores como autores do processo é algo que têm nos preocupado muito e que vem sendo sinalizado por diversos autores a partir dos anos 90 do século XX. Nesse sentido, Sacristán e Gómez (1998, p. 125), advogam que “o currículo são os conteúdos, o guia do progresso pela escolaridade”, justificando esse entendimento pelo fato de a escola, espaço inserido em um sistema de educação formal, ter a necessidade de ser organizada e servir a interesses sociais que inevitavelmente terão consequências decisivas nos sujeitos formados que, portanto, tendem a ser controláveis. Desta forma, cabe ao professor assumir esse papel, comprometido com a regulação e controle acerca da distribuição do conhecimento, expressando, assim, o que é e o que não é objeto de ensino e estabelecendo a ordem de sua distribuição.

Nesse sentido, Lopes e Macedo (2011), destacam alguns, dos que consideram, principais problemas da interpretação curricular, apontando como um deles o

[...] de colocar em lados opostos saberes sociais com os quais interpretamos o mundo, como se pudéssemos sempre estar categorizando os diferentes saberes, do ponto de vista epistemológico, sem considerar o hibridismo entre os saberes e diferentes contextos das práticas sociais de legitimação e de produção desses mesmos saberes (LOPES; MACEDO, 2011, p. 91).

Nessa categoria, identificamos, ainda, excertos na pesquisa de Matos (2018), em P9, ao destacar que

os docentes do Ensino Fundamental II, em sua grande maioria, não se sentem participantes do processo de construção curricular, a utilização do Currículo Referência é feita de maneira imposta e obrigatória o que, segundo eles, retira sua autonomia no ensino de Ciências da Natureza (MATOS, 2018, p. 10). 
A autora analisou compreensões de professores da educação básica a partir do processo de implantação de um Currículo de Referência no estado de Goiás, e ressalta que

com a análise das respostas dos docentes percebe-se que eles entendem o Currículo Referência utilizado no estado de Goiás, e na cidade de Goiânia, como um instrumento que é imposto pelo Governo, consequentemente pela SEDUCE, e não se sentem participantes da construção do mesmo (MATOS, 2018, p. 105).

Em análise, também, a um processo de implantação curricular, em P10, Tamanini (2018), defende que

[...] os currículos (assunto de relevância e de uma vastidão de pesquisas importantes, porém, que não será aprofundado neste trabalho) podem servir como significativas diretrizes para os professores no ensino de Ciências, contudo, não devem cercear a autonomia didática nem pedagógica dos professores (TAMANINI, 2018, p. 60).

Fortalecendo a categoria, destacamos que tal compreensão foi destacada por Lima (2008), em P2, ao compartilhar que, “[...] o currículo do Centro passa a ser fortemente dirigido para o vestibular, perdendo o foco da integração" (LIMA, 2008, p. 76). O autor, em sua dissertação, investigou aspectos didáticos, pedagógicos e epistemológicos de professores atuantes e em formação.

Lopes (2006, p. 628), contribui ao ressaltar a importância de "produzir nexos entre a diversidade da prática pedagógica e relações mais gerais", ou seja, entre as instâncias macro e micro. Ainda, a autora afirma que, caso estes nexos não sejam desenvolvidos, "é possível constituir um determinismo ás avessas: a microanálise gerando conclusões macro sem mediações". Outro aspecto ao qual a autora chama a atenção é em relação a investigação da concepção de professores, em que, de acordo com ela, é necessário conduzir esse processo com cautela, pois, "as concepções identificadas em um pequeno número de professores são associadas ao universo do professorado de forma imediata e utilizadas para justificar problemas no desenvolvimento dos currículos."

Com essas considerações, percebemos que esta categoria evidencia um processo de recontextualização por hibridismo ainda efetivamente incipiente, pois os discursos analisados permitem inferir que o professor exclusivamente procura cumprir com o que está prescrito nos documentos curriculares e não manifestando indícios de reflexão, ou de sua participação neste processo. Dessa forma, passamos à discussão da segunda categoria analisada.

\subsection{COMPREENSÃo CURRICULAR SOB A PERSPECTIVA CONTEUDISTA-CRÍTICA}

A compreensão de certo nível de afastamento ao processo de construção curricular na escola foi identificada, também, em três trabalhos, são eles P3, P4, e P5, todavia, identificamos a busca por aproximação dos professores ao processo de colocar o currículo em prática na 
escola e um dos instrumentos apontados para essa aproximação foi o livro didático. Compreendemos que, ao reconhecer o livro didático como um instrumento que faz o currículo acontecer na escola, demonstra um esforço do professor em se aproximar do currículo prescrito. Tal perspectiva foi evidenciada nos trabalhos de Capeloto (2010) que corresponde a P3, Pereira (2011), P4, e Silva (2013), correspondente a P5.

No estudo apresentado por Capeloto (2010), que em sua dissertação estuda as contribuições dos Parâmetros Curriculares Nacionais para as práticas pedagógicas dos professores dos anos iniciais do ensino fundamental, a autora destaca que

[...] os resultados revelam que os professores conhecem o PCN e acreditam que esse referencial influencia suas práticas de Ciências Naturais. Pelas análises, percebemos que essa influência se dá, muitas vezes, de forma indireta, pelo uso do livro didático, o material mais utilizado, pelos professores que fizeram parte do estudo, para a seleção e ordenação dos conteúdos e na escolha das atividades didáticas (CAPELOTO, 2010, p. 08).

Ainda, a autora reforça que, "pelas respostas notamos que o livro didático aparece como importante norteador no processo de seleção de conteúdos, ou seja, ele representa um guia a partir do qual os professores efetivam seu trabalho" (CAPELOTO, 2010, p. 95).

O livro didático vem sendo objeto de estudos em pesquisas que buscam analisar o currículo brasileiro há alguns anos, de acordo com Megid Neto e Fracalanza (2003, p. 154), "pode-se dizer que os atuais livros didáticos de Ciências correspondem a uma versão livre das diretrizes e programas curriculares oficiais em vigência”. Com isso, Güllich (2012, p. 14), afirma que

o livro didático tem assumido mais que o currículo-conteúdo, uma dinâmica que se apresenta na recontextualização dos discursos educacionais acerca das políticas e programas educacionais curriculares, o desenho metodológico e a produção de aula e a própria formação dos professores de Ciências.

A perspectiva de aproximação dos professores com os documentos curriculares que, mesmo que ocorra de maneira inconsciente, é um aspecto que contribui na estruturação de suas compreensões de currículo, como a autora sugere "mesmo que não percebam, ao utilizarem livros didáticos submetidos a uma avaliação que considera as diretrizes presentes nos PCN, os professores acabam incorporando, em suas práticas, concepções e ideias presentes nesse documento" (CAPELOTO, 2010, p. 97).

Na pesquisa, Capeloto (2010) evidenciou ainda, que a desconsideração dos contextos escolares por parte dos documentos curriculares dificulta a incorporação pelos professores, “entendemos que as prescrições precisam ser interpretadas e compreendidas pelos professores, 
os agentes executores do currículo na prática" (CAPELOTO, 2010, p. 112). Essa percepção é reforçada pela autora ao apresentar os resultados da pesquisa em que

[...] as orientações didáticas preconizadas pelos PCN são muito pouco utilizadas. Embora o documento recomende a realização de observações, experimentos, e enfatize a problematização como uma estratégia para a promoção de mudança conceitual, as respostas não fazem qualquer referência a esse tipo de abordagem [...] (CAPELOTO, 2010, p. 126).

Identificamos, também, a compreensão conteudista-crítica em uma professora (sujeito da pesquisa) investigada na pesquisa apresentada por Pereira (2011). A autora defende em sua tese o processo de legitimação do saber científico com base no conceito de discurso de Laclau, e, compreende que o currículo parte das necessidades dos alunos e não de conteúdos, pois "na entrevista, Dora disse claramente que está comprometida em favorecer o engajamento das crianças com os cuidados que precisam assumir desde cedo" (PEREIRA, 2011, p. 144).

No estudo realizado, Pereira (2011), destaca a ênfase no processo disciplinar por recomendação e organização curricular, porém a pesquisadora acena que a professora não se vê afastada dos documentos curriculares e vai buscando caminhos para a aproximação. Para tanto, relata que "essas observações são pistas que evidenciam que a professora está atenta e procura contextualizar as atividades, de forma a tornar os conteúdos mais próximos do cotidiano da criança” (PEREIRA, 2011, p. 145).

Ao longo da tese, Pereira (2011) ressalta que a professora se sente contemplada pelos documentos curriculares da maneira como são prescritos e atribui a própria prática a necessidade da aproximação. Ainda, destaca como uma das características da professora "o seu posicionamento crítico e o seu discernimento para desenvolver suas aulas a partir das propostas de que dispõe, mas tem como foco as demandas de seus alunos, suas características e potencialidades" (PEREIRA, 2011, p. 148).

No entanto, mesmo com um posicionamento mais crítico de professores em relação à prática e, por conta disso, em relação ao currículo, ainda há dificuldades na superação do entendimento do currículo como artefato, sendo visto como distante do conhecimento construído na escola. Conforme a autora:

[...] embora valores, posturas e afetos se constituam como currículo enunciado nos contextos observados, as professoras têm dificuldade de romper com a concepção de currículo como artefato e que pressupõe a possibilidade de introdução do educando em uma cultura previamente estabelecida (PEREIRA, 2011, p. 171).

Na dissertação de Silva (2013), identificamos que o autor procura estabelecer relações entre a formação docente em Pedagogia e a concepção dos professores sobre o Ensino de Ciências nos anos iniciais. Na mesma linha de Pereira (2011) e Capeloto (2010), a pesquisa de 
Silva (2013), apresenta contribuições que robustecem a nossa categoria conteudista-crítica de compreensões curriculares. No excerto da fala de uma professora, apresentada no estudo, destacamos o cuidado em relacionar os conteúdos com o dia-a-dia dos estudantes:

Sempre que eu vou dar um assunto novo do livro, eu penso assim: o que é que eu posso trazer do cotidiano para isso aqui? Que relação esse assunto tem com o mundo deles? Porque assim eles ficam mais curiosos, querendo saber, e isso é bom, porque ajuda demais na compreensão do que eu estou explicando (professora D) (SILVA, 2013, p. 93).

Por meio do excerto, acenamos a estreita relação do currículo com o livro que a professora externaliza. Na pesquisa realizada, Silva (2013) deflagra a preocupação da professora ao afirmar que:

Nesse discurso, podemos atestar que a preocupação central da professora se restringe a contextualizar os conteúdos, fazer uma aproximação entre o que o livro traz e o que o aluno vive. Ela concebe a contextualização como potencializadora da aprendizagem, como uma possibilidade de se estabelecer relações entre os novos conceitos apresentados e o universo dos seus alunos (SILVA, 2013, p. 93).

Ao buscar a aproximação dos conteúdos científicos com o dia-a-dia do aluno, os professores demonstram comprometimento com o processo de aprendizagem dando ênfase ao conhecimento cotidiano como alicerce do conhecimento construído em sala de aula. Nessa linha, Silva (2013) contribui ao relacionar o que está prescrito nos documentos escolares e o que é realizado pela professora em sala de aula. Para o autor,

percebe-se o tratamento de dois aspectos que contribuem para a ampliação das possibilidades de aprendizagem do aluno e que comungam com as propostas elencadas nos PCN/CN, o papel ativo do aluno como sujeito da aprendizagem e a abordagem do conteúdo vinculada à sua realidade (SILVA, 2013, p. 114).

Nesse enredamento, está a categoria compreensão curricular sob a perspectiva conteudista-crítica, elaborada sobre os argumentos apresentados como possibilidades de aproximação dos professores com documentos curriculares e com a construção do currículo no dia-a-dia da escola. Assim, temos o livro didático como um instrumento de aproximação curricular, conforme apontado por Güllich (2012). Além disso, a consideração dos contextos escolares aparece nos três trabalhos desta categoria como um potencializador do processo de aproximação. Outros importantes pontos apresentados são: a importância do posicionamento crítico do professor, o envolvimento com os documentos curriculares mesmo que de forma inconsciente, e, ainda, a diferença entre o que pode representar a prática e o que está recomendado nos documentos.

A perspectiva crítica, ainda incipiente nas compreensões de professores da área de Ciências da Natureza acerca do currículo na Educação Básica, é aspecto fundamental no 
desenvolvimento da autonomia docente, conforme defendido por Delanogari e Leite (2018, p. 55), “o pensar crítico contribui para o processo da construção da autonomia, pois, ao percebermos aspectos que podemos mudar, buscamos estudar mais, refletir acerca das práticas e passamos a adquirir autonomia".

Assim sendo, Lopes e Macedo (2011, p. 77, grifos das autoras) contribuem ao afirmarem que "a perspectiva crítica de forma muito mais contundente problematiza o que se entende por conhecimento e lança as bases para que seja questionado o que conta como conhecimento escolar". Ainda, com base nas autoras as discussões na perspectiva crítica possibilitam que o conhecimento deixe de ser considerado neutro, pois, não basta "apenas discutir $o$ que selecionar, quais critérios utilizar nessa seleção, mas efetuar a crítica do conhecimento produzido e dos seus modos de produção, ao mesmo tempo que problematizam por que determinados conhecimentos são selecionados e outros não".

Dessa forma, a categoria compreensão curricular sob a perspectiva conteudista-crítica revela elementos que marcam a transformação da forma de pensar dos professores, ou seja, percebe-se que a recontextualização por hibridismo dos discursos ainda está fortemente atrelada a conteúdos pré-estabelecidos, porém são evidenciados entendimentos acerca das contribuições do planejamento docente para o processo de construção curricular.

\subsection{CURRÍCULO ESCOLAR SOB UMA COMPREENSÃO CRÍTICO-REFLEXIVA}

A categoria currículo escolar sob uma compreensão crítico-reflexiva foi identificada no trabalho P6. Compreendemos que caracteriza uma compreensão mais congruente de currículo, ao evidenciar que a recontextualização dos discursos oficiais, nas instâncias micro, ocorre de forma mais qualificada. O estudo realizado trata de uma tese de doutorado em que o autor analisa compreensões de currículo apresentadas por professores da área de Ciências da Natureza em escolas de educação básica da região das Missões/RS. De acordo com o autor, "a pesquisa indica que os professores procuram trabalhar os conteúdos de acordo com cada realidade escolar" (FENNER, 2014, p. 7).

No texto, identificamos um contexto de construção curricular permanente. Os professores entrevistados relatam historicamente como o processo de reconhecimento curricular foi sendo construído na escola, por meio da participação de todos e, em especial, pelo espírito de coletividade que foi desenvolvido ao longo dos anos. Fenner (2014), ressalta que as necessidades da escola compõem a construção de um currículo, dentro e pela realidade escolar, em que, interpretando os aspectos externos e considerados na construção dos "projetos da 
escola", tudo é adequadamente adaptado para as necessidades. Quanto a isso Fenner (2014) apresenta:

o grupo de professores, embora de escolas e localidades diferentes, tem em comum acreditar que todo currículo é construído cotidianamente. Deve também ser contextualizador e buscar novas formas de organização para reduzir o isolamento e a fragmentação entre as diferentes disciplinas curriculares (FENNER, 2014, p. 37).

A compreensão crítico-reflexiva dos professores, evidenciada na pesquisa de Fenner (2014) se mostra fascinante, considerando a permanente construção/reconstrução curricular como intenção das escolas analisadas. O processo de reconstrução permanente de currículo apresentado se aproxima da perspectiva proposta por Moraes (2004). O autor defende “currículos abertos e flexíveis em seus conteúdos" e, discute a "necessidade de uma permanente contextualização dos currículos, razão a mais para sua permanente reconstrução" (MORAES, 2004, p. 40).

No estudo analisado, Fenner (2014) defende o currículo como um dinamizador dentro da escola, que deve atingir os diferentes âmbitos para reflexão e problematização. De acordo com o autor, todas as escolas pesquisadas "apontam que currículo é um contexto globalizado. É um instrumento de compreensão do mundo e para a transformação social. Tudo que se faz na escola, sistematizado ou não, é currículo" (FENNER, 2014, p. 39).

A função social do currículo escolar também foi sinalizada nas compreensões dos professores entrevistados na pesquisa. Além disso, identificamos no estudo que o currículo deve “fazer a ponte, a ligação, entre a sociedade e a escola. É ele que irá encurtar espaços para que a escola saiba o que a sociedade espera dela e a própria escola possa mostrar para a sociedade a sua proposta de formação" (FENNER, 2014, p. 54).

Tal como a função social, outro destaque que caracteriza essa categoria é a relevância atribuída ao processo de reflexão dos professores, nesse movimento de construção curricular, uma vez que, a problematização acerca da reflexão do professor sobre a sua prática, seu cotidiano escolar e a sua participação na construção do currículo é o que diferencia esse trabalho (P6), contribuindo para uma compreensão curricular mais qualificada. De acordo com Fenner (2014, p. 67), “com relação ao professor reflexivo, ele busca significar e construir pessoas e histórias com base nas experiências vividas. Ele oferece estrutura para o seu crescimento e o de seus alunos".

Ainda, fortalecendo a perspectiva crítico-reflexiva identificada, o autor destaca que

a reflexão implica sempre uma análise crítica do trabalho que realizamos. Fazendo uma reflexão sobre nosso trabalho, estamos questionando sua validade, o significado que ele tem para nós e para os sujeitos com quem trabalhamos, bem como para a 
comunidade da qual fazemos parte e que estamos construindo através de nossas práticas diárias. Toda e qualquer resposta às questões que nos propomos só pode ser encontrada em dois espaços: no da nossa prática, da experiência cotidiana da tarefa que procuramos realizar, e no da reflexão crítica sobre os problemas que essa prática faz surgir como desafios para o professor (FENNER, 2014, p. 69).

Da mesma forma, o autor cita que

[...] é importante compreender que a competência do professor reflexivo é ter a capacidade de compreender o mundo, os outros e seus pares. Saber refletir com a coletividade, ouvir a si mesmo e aos outros, é indispensável para a vivência da cidadania. A compreensão conduz e prepara para a mudança, para o incerto, para a vivência com outras circunstâncias e fortalece a interação, a contextualização e a colaboração dentro de uma instituição escolar e na sociedade (FENNER, 2014, p. 75).

O autor (FENNER, 2014), ressalta ainda, a imprescindível participação dos professores no processo de construção do currículo. Para ele, é importante que estejam engajados com a escola, principalmente nas elaborações de seus projetos político-pedagógicos. Conforme proposto:

\begin{abstract}
A participação de professores na construção dos conteúdos acontece sempre que necessário, principalmente quando a escola reconstrói seu Projeto PolíticoPedagógico. A minha participação na reconstrução sempre se dá junto, sempre tentando, sempre interferindo, sempre dando opiniões, certo ou errado, mas tentando ajudar (Claudete) (FENNER, 2014, p. 100, grifo do autor).
\end{abstract}

No estudo, deflagra-se a ideia de currículo em movimento, que é um aspecto que caracteriza a categoria crítico-reflexiva, um currículo que se movimenta, que muda e se molda às necessidades de cada escola. Nesse sentido, o autor destaca que

[...] a construção de um currículo voltado para a realidade do estudante depende da filosofia de cada escola. Cada escola sabe o que deseja para seu estudante, sabe o que precisa ensinar para que os mesmos consigam atingir os anseios dessas instituições. Por isso, os conteúdos muitas vezes são ensinados de forma diferenciada, pois cada escola tem estudantes com características, peculiaridades e desejos diferentes (FENNER, 2014, p. 101).

Nesse sentido, a escola, usufruindo da autonomia que possui, com suas escolhas, objetivos e filosofias, determina como vai acontecer a construção de seu próprio currículo, que se movimenta, sempre dialogando com seus professores para que isso ocorra de forma tranquila, e oportunizando aos alunos diferentes possibilidades de aprendizagem, o que torna o currículo ainda mais enriquecedor, pois, segundo o autor,

a escola trabalha, além dos conteúdos, com projetos de pesquisa, e oportuniza que os
professores possam trabalhar de maneira diferenciada os conteúdos, os conceitos na
sala de aula. Como afirma o professor de Química: Participar da reconstrução e dos
projetos de pesquisa possibilita que muita coisa poderia mudar, já que a gente tem
aquela ideia de currículo como uma grade, parece algo aprisionado, tem que ser
trabalhado daquela forma, daquele jeito, acho que seria interessante fazer algo
diferente. Existem projetos que a gente estuda, a parte pedagógica vem e diz, você
tem esse tipo de trabalho para ser feito, sobre determinado assunto, então cada área
elabora de que forma irá abordar aquilo. Essa parte eu acho bem interessante, a 
coordenadora deixa livre para montar o projeto. Essa liberdade que eu acho que às vezes é bom no currículo. Você ter essa flexibilidade de ter conteúdos para trabalhar, mas adaptar eles para uma realidade que tem interesse dos alunos (Armindo) (FENNER, 2014, p. 102, grifo do autor).

A liberdade dada aos professores, referida no excerto retirado do estudo, representa o quanto o currículo permanece em movimento, pois cada professor colabora, dentro de sua área de atuação, para que isso aconteça, e o faz com dedicação, competência e, principalmente, com a consciência da importância de sua participação nesse processo. O professor sente-se valorizado neste espaço de construção curricular e se vê como autor do currículo.

As categorias identificadas nesse estudo evidenciam aproximações com o estudo de Leite e Zanon (2018). Na pesquisa realizada, as autoras defendem o desenvolvimento de dois estilos de pensamento, sendo um conservador e outro transformador, pelos professores. Podemos aferir que a categoria compreensão conteudista-ingênuo sobre currículo escolar, se aproxima do estilo de pensamento conservador e a categoria currículo escolar sob uma compreensão crítico-reflexiva do estilo de pensamento transformador (LEITE; ZANON, 2018). Na pesquisa realizada, as autoras citam,

[...] que um dos professores do grupo com EP conservador relatou que 'Currículo é uma seleção de conteúdos das várias disciplinas que compõe os componentes curriculares', já outro professor do grupo de EP transformador apresenta que 'O Currículo Escolar é tudo o que desenvolvemos e realizamos no colégio em função dos alunos e vai muito além de uma lista de conteúdos que são trabalhados em sala de aula durante um ano letivo' (LEITE; ZANON, 2018, p. 968).

Portanto, o presente estudo reforça nossos entendimentos acerca da importância em investir em processos de formação permanente acerca do currículo escolar a fim de contribuir com entendimentos críticos e reflexivos. Somente assim os professores, no contexto micro, terão possibilidade de desenvolver autonomia para construírem os seus próprios currículos.

Com essas considerações percebemos que a categoria crítico-reflexiva se aproxima de forma efetiva de uma recontextualização por hibridismo, que contribui para o desenvolvimento de um currículo mais completo, atendendo mais adequadamente as demandas atuais, que se constrói em meio e principalmente por meio da prática pedagógica diária, que não vem finalizado, imposto por órgãos externos que nada compreendem da realidade de muitas escolas.

\section{CONSIDERAÇÕES FINAIS}

No presente texto analisamos pesquisas da área em nível stricto sensu, acerca da temática: Currículo e o ensino de Ciências. Para tanto, realizamos um estudo documental em dissertações e teses publicadas no BDTD a fim de identificar compreensões de professores da educação básica. Foram investigados dez trabalhos, sendo três teses de doutorado e sete 
dissertações, em que os autores realizaram estudos com professores de educação básica por meio de questionários ou entrevistas.

O processo de análise dos trabalhos fez emergir três categorias de compreensões: compreensão conteudista-ingênuo sobre currículo escolar, compreensão curricular sob a perspectiva conteudista-crítica e currículo escolar sob uma compreensão crítico-reflexiva. Destacamos que as categorias evidenciam o processo de hibridismo de discursos curriculares, conforme apresentado por Lopes (2005), em virtude de problematizarem a compreensão curricular e a participação dos professores nesta construção. Por meio da leitura dos trabalhos, acenamos que a compreensão conteudista-ingênuo prevalece nos discursos dos professores, o que nos preocupa, considerando a dificuldade do professor em se reconhecer como autor do processo.

Dessa forma, suscitamos a questão de que o problema ou, os problemas identificados e elencados ao longo do estudo em relação às compreensões curriculares, como a ingenuidade, a carência de criticidade e reflexão, podem estar precisamente relacionados á recontextualização por hibridismo, ou até mesmo, a maneira como essa recontextualização ocorre.

Reiteramos, ainda, que o currículo escolar sob uma compreensão crítico-reflexiva se configura como uma possibilidade no processo de superação das concepções dos professores integrantes das categorias compreensão conteudista-ingênuo sobre currículo escolar, compreensão curricular sob a perspectiva conteudista-crítica. Pensar o currículo da forma como esta categoria o apresenta contribui para uma realidade escolar recontextualizadora e fortalece o entendimento dos professores quanto ao processo de participação na construção do currículo na prática, para que, aos poucos, isso deixe de ocorrer de forma ingênua e se torne um propósito consciente do professor.

Por fim, consideramos que o presente estudo possibilitou a emergência de conhecimentos, que ampliam as compreensões sobre currículo no ensino de Ciências, principalmente a respeito de compreensões curriculares dos professores, para que outros pesquisadores, sejam da área de currículo ou não, sintam-se provocados a despertar reflexões e discussões acerca deste tema que é tão importante no contex to educacional brasileiro.

\section{REFERÊNCIAS}

BARDIN, Laurence. Análise de Conteúdo. 1 Ed. São Paulo: Edições, 2011.

BRAGA, André. Os saberes de professores que ensinam ciências nas séries iniciais - um estudo de caso. 2005.146 p. Dissertação (Mestrado em Educação - Metodologia de ensino) Curso de pós-graduação em Educação, Universidade Federal de São Carlos, São Carlos, SP, 
2005. Disponível em: https://repositorio.ufscar.br/handle/ufscar/2784? show=full. Acesso em: 23 mar. 2019.

CAPELOTO, Larissa Regina. Dez anos dos Parâmetros Curriculares Nacionais: contribuições para o ensino de ciências naturais nos anos iniciais do ensino fundamental I. 2010.135 f. Dissertação (Mestrado em Educação Escolar) - Programa de Pós-Graduação em Educação Escolar, Universidade Estadual Paulista, Faculdade de Ciências e Letras, Araraquara, SP, 2010. Disponível em: https://repositorio.unesp.br/handle/11449/90118. Acesso em: 23 mar. 2019.

CARMINATTI, Bruna. A construção da interdisciplinaridade a partir dos saberes docentes nas ciências naturais: a realidade de duas escolas públicas do norte do rio grande do sul. 2015. 156 f. Dissertação (mestrado em Educação em Ciências) - Programa de pós-graduação em Educação em Ciências: Química da Vida e Saúde, Universidade Federal do Rio Grande do Sul, Porto Alegre, RS, 2015. Disponível em:

https://www.lume.ufrgs.br/handle/10183/114669. Acesso em: 23 mar. 2019.

DELANOGARI, Franciele Noro; DE ANDRADE LEITE, Fabiane. A reestruturação curricular do ensino médio no Rio Grande do Sul: perspectivas e desafios. Ensino \& Pesquisa, v. 16, n. 1, 2018. Disponível em: http://periodicos.unespar.edu.br/index.php/ensinoepesquisa/article/view/1008. Acesso em 27 jul. 2019.

FENNER, Roniere Dos Santos. Currículo de ciências da natureza: $O$ processo de reconstrução do projeto político-pedagógico na Escola pública de ensino médio. 2014. 145 f. Tese (Doutorado em Educação em Ciências) - Curso de pós-graduação em Educação em Ciências: Química da Vida e da Saúde, Universidade Federal do Rio Grande do Sul, Porto Alegre, RS, 2014. Disponível em: https://lume.ufrgs.br/handle/10183/109721. Acesso em: 23 mar. 2019.

FLECK, Ludwik. Gênese e Desenvolvimento de um Fato Científico. Trad. Georg Otte, Mariana Camilo de Oliveira. Belo Horizonte: Fabrefactum, 2010.

GÜLLICH, Roque Ismael da Costa. O livro didático, o professor e o ensino de ciências: um processo de investigação-formação-ação. 2012. 263 f. Tese (Doutorado em Educação nas Ciências) - Programa de Pós-graduação em Educação nas Ciências, Universidade do Noroeste do Estado do Rio Grande do Sul - UNIJUÍ, Ijuí, RS, 2012. Disponível em: https://bibliodigital.unijui.edu.br:8443/xmlui/handle/123456789/2043. Acesso em: 17 jun. 2019.

KRASILCHIK, Myriam. Reformas e realidade: o caso do ensino das ciências. São Paulo em Perspectiva, v. 14, n. 1, 2000, p. 85-93. Disponível em: https://www.scielo.br/pdf/spp/v14n1/9805.pdf. Acesso em 11 jun. 2019.

LEITE, Fabiane de Andrade; ZANON, Lenir Basso. Estilos de pensamento de professores da área de Ciências da Natureza e o processo de autonomia compartilhada. Ciência \& Educação (Bauru), v. 24, n. 4, p. 959-977, 2018. Disponível em: https://www.scielo.br/pdf/ciedu/v24n4/1516-7313-ciedu-24-04-0959.pdf. Acesso em 22 jul. 2019. 
LIMA, Adriel Roberto Ferreira de. Atividade Interdisciplinar no ensino de Ciências: entre o ideal e a realidade. 2008. 93 f. Dissertação (Mestrado em Educação) - Programa de PósGraduação em Educação, Universidade Federal de Pernambuco. Recife, PE, 2008. Disponível em: https://repositorio.ufpe.br/handle/123456789/4331. Acesso em: 23 mar. 2019.

LOPES, Alice Casimiro. Recontextualização e Hibridismo. Currículo sem fronteiras, v. 5, n. 2, 2005, p. 50-64. Disponível em:

https://www.curriculosemfronteiras.org/vol5iss2articles/lopes.pdf. Acesso em 14 jun. 2019.

LOPES, Alice Casimiro. Relações macro/micro na pesquisa em currículo. Cadernos de Pesquisa. v. 36, n. 129, 2006, p. 619 - 635. Disponível em:

https://www.scielo.br/pdf/cp/v36n129/a0636129.pdf. Acesso em 14 jun. 2019.

LOPES, Alice Casimiro. Políticas de Integração Curricular. 1 ed. Rio de Janeiro: EdUERJ, 2008.

LOPES, Alice Casimiro; MACEDO, Elizabeth. Currículo: debates contemporâneos. 3 ed. São Paulo: Cortez, 2010, 240 p.

LOPES, Alice Casimiro; MACEDO, Elisabeth. Teorias de currículo. São Paulo: Cortez, 2011, p. 280.

LÜDKE, Menga; ANDRÉ, Marlí E. D. A Pesquisa em educação: abordagens qualitativas. $2^{\text {a }}$ ed. Rio de Janeiro: E.P.U., 2013, p. 128.

MATOS, Milena de Oliveira. O Currículo e o seu papel no ensino: compreensão de docentes de Ciências da Natureza do Ensino Fundamental II de Escolas Estaduais em Goiânia. 2018. 122 f. Dissertação (Mestrado em Educação em Ciências e Matemática) Programa de pós-graduação em Educação em Ciências e Matemática, Universidade Federal de Goiás. Goiânia, GO, 2018. Disponível em:

http://repositorio.bc.ufg.br/tede/handle/tede/8913. Acesso em: 23 mar. 2019.

MEGID NETO, Jorge; FRACALANZA, Hilário. O livro didático de ciências: problemas e soluções. Ciência \& Educação (Bauru). v. 9, n. 2, 2003, p. 147-157. Disponível em: https://www.scielo.br/pdf/ciedu/v9n2/01.pdf. Acesso em: 25 jun. 2019.

MELO, Franklin Júlio de. Conhecimentos profissionais da docência no ensino de ciências no contexto do programa São Paulo faz escola e do SARESP. 2016. 147 f. Dissertação (Mestrado em Educação para a Ciência) - Programa de pós-graduação em Educação para a Ciência, Universidade Estadual Paulista- Faculdade de Ciências, Bauru, SP, 2016. Disponível em: https://repositorio.unesp.br/handle/11449/152294. Acesso em: 23 mar. 2019.

MORAES, Roque. Ninguém se banha duas vezes no mesmo rio: currículos em processo permanente de superação. In: MORAES, Roque; MANCUSO, Ronaldo (Org.). Educação em Ciências: produção de currículos e formação de professores. Ijuí: Unijuí, 2004. p. 15 - 42.

MOREIRA, Antonio Flavio Barbosa. O campo de currículo no Brasil: construção no contexto da ANPED. Cadernos de Pesquisa. n.117, 2002, p. 81-101. Disponível em:

https://www.scielo.br/scielo.php?pid=S010015742002000300005\&script=sci_abstract\&tlng= pt. Acesso em: 25 jun. 2019. 
PEREIRA, Talita Vidal. Tradição e inovação: sentidos de currículo que se hibridizam nos discursos sobre o ensino de Ciências nos anos iniciais do Ensino Fundamental. 2011. 199 f. Tese (Doutorado) - Programa de Pós-graduação em Educação, Universidade do Estado do Rio de Janeiro, Rio de Janeiro, RJ, 2011. Disponível em:

http://bdtd.ibict.br/vufind/Record/UERJ_5cbe646d9a5f57676f756ad9dd8d65cb. Acesso em: 23 mar. 2019.

SACRISTÁN, José Gimeno; GÓMEZ, Perez Ángel. Compreender e transformar a escola. 4. ed. Porto Alegre: Artmed, 1998.

SILVA, Maurílio Mendes da. Relação entre a formação docente para os anos iniciais e a concepção dos professores sobre o ensino de Ciências. 2013. 167 f. Dissertação (Mestrado em Ensino de Ciências) - Programa de Pós-graduação em Ensino das Ciências, Universidade Federal Rural de Pernambuco, Recife, PE, 2013. Disponível em:

http://www.tede2.ufrpe.br:8080/tede2/bitstream/tede2/5396/2/Maurilio\%20Mendes\%20da\%2 0Silva.pdf. Acesso em: 23 mar. 2019.

TAMANINI, Tiago Amador. Interfaces disciplinares: ensaios e teorizações de Práticas educativas para integrar disciplinas no ensino de Ciências. 2018. 227 f. Tese (Doutorado em Educação em Ciências) - Programa de pós- graduação Educação em Ciências Química da Vida e Saúde, Universidade Federal do Rio Grande do Sul, Porto Alegre, RS, 2018.

Disponível em: https://lume.ufrgs.br/handle/10183/187399. Acesso em: 23 mar. 2019.

Recebido em: 25 de junho de 2020.

Aprovado em: 31 de agosto de 2020. 